\title{
A developed SW tool for a LCC model evaluation of a Stage Pre-IIIB to Stage IIIB NRMM-compliant vehicle
}

\author{
L. Della Ragione ${ }^{1}$, G. Meccariello ${ }^{1}$, F. Sperandio ${ }^{2}$, \\ M. Basso ${ }^{2} \&$ A. Al-Sened ${ }^{3}$ \\ ${ }^{1}$ Istituto Motori, CNR National Research Council, Italy \\ ${ }^{2}$ D'Appolonia S.p.A, Italy \\ ${ }^{3}$ The Engine Consultancy Ltd., UK
}

\begin{abstract}
The scope of this paper is to explain the main concepts and characteristics of the LCC model for the new subsystem to fulfil NRMM Directive Stage IIIB requirements on emissions. In particular, an after treatment device and emerging technology solutions will be considered to evaluate the delta cost of new corrective and preventive maintenance plans.

The LCC model is a Delta-LCC tool, with respect to previous Stage IIIB, where all the additional costs relevant to acquiring and managing vehicles powered with NRMM-compliant engines are compared with the equivalent costs currently sustained. The Delta-LCC model of each type of vehicle concerned is a SW tool, developed in the Microsoft Excel environment. It could be used to estimate and compare the LCC of different alternative solutions or to perform an impact analysis, as far as cost issues are concerned. It could also be used to support the Political/Legal, Economic, Social, Technical and Environmental impact (PESTLE) analyses. The Delta-LCC model structure will include development costs; manufacturing and installation costs; operation and maintenance costs; and decommissioning costs.

The paper describes the development of such a tool and, as a case study based on literature data, focuses on its application in supporting the evaluation of cost integration of a diesel engine builder in a new rail vehicle.

Keywords: Stage IIIB NRMM, Delta-LCC, diesel locomotive.
\end{abstract}




\section{Introduction}

The new EU standards and regulations, referring to the Non-Road Mobile Machinery (NRMM) Directive Stage IIIB, must not only increase the level of environmental protection but also safeguard the commercial competitiveness of the mode while reducing dependence on fossil fuels, reducing exhaust emissions, improving design and offering a systematic approach to noise and vibration. In this context, the modifications enforce the rail industry to upgrade itself in terms of engines and loco technology.

Normally decisions concerning new equipment or subsystems, such as the installation of the DPF (Diesel Particulate Filter) or DOC (Diesel Oxidation Catalyst) or any other sub-systems, to reduce pollutant emissions, involve the analysis of benefits and costs, some with quantifiable monetary values and some without. Ideally, decisions to proceed with implementation will be made only in those cases where quantifiable benefits outweigh projected costs, unless other considerations, such as public safety, are predominant. In any case, for decisions with public implications, both of new costs and of public safety, it is extremely interesting to have a straightforward benchmark monetary analysis. Lack of exact data relating to operations and maintenance costs, expected productivity and efficiency improvements, and quantification of potential benefits could be an impediment to the realization of cost/benefit analysis. However, data from literature and engineering experience could be used when available. In general, it is clearly interesting to receive information from a number of equipment suppliers (including strategic partners), rail transportation staff, public safety officers and local government staff to introduce realistic data in some cost/benefit analysis and then in a Life Cycle Cost evaluation model [1].

In literature many general considerations can be recognised on Life Cycle Cost use and opportunity. Awalegaonkar et al. [2] recommend the railway companies to embrace a Life Cycle Total Cost, adopting integrating strategies to a rail asset from the time it is purchased until it is disposed of. The application of the TCO can reduce capital and operating costs by a total of 10 percent to 25 percent. For locomotives, the biggest item is fuel, which can account for 75 percent of a locomotive's total lifetime costs. Also they confirm that taking a life-cycle TCO approach can reduce costs and extend the life of the asset.

In [3] the authors examine different technologies existing for non-road diesel engines to meet new emission standards. EPA has recently set emission limits for non-road engines and for locomotive engines, through combinations of combustion chamber improvements, fuel injection improvements, advances in low temperature charge air cooling, and exhaust gas recirculation. So they examine the costs to upgrade these engines with new or improved turbo charging and, after cooling, to meet new emission limits.

In [4] it is examined which propulsion and energy storage configurations of a diesel-electric hybrid locomotive lead to the lowest life cycle costs using evolutionary multicriteria optimisation methods. Life cycle costs are computed determining acquisition costs, consumption costs and costs of maintenance 
within a particular configuration. Also the weight of the different components is considered in respect of their influence on fuel consumption.

In literature no comparisons for rail applications of the advantages and disadvantages of Selective Catalytic Reduction vs. Exhaust Gas Re-circulation have been found.

\section{Diesel locomotive fleet status}

Based on the UIC statistics, there are around 17,640 diesel locomotives and 8775 diesel railcars in operation in UIC member railways [1]. To crosscheck these UIC values the two additional sources Jane's World Railways (JWR) and statistics from www.Railfaneurope.net (RFE) have been used, showing a comparable vehicle proportion of one-third for railcars and two-thirds for locomotives.

Table 1: Number of diesel locomotive and railcar vehicles in UIC-members fleets (source: UIC statistics, Jane's World Railways (2004-2005), Railfaneurope.net).

\begin{tabular}{|c|c|c|}
\hline $\begin{array}{l}\text { UIC member diesel vehicle numbers } \\
\text { Source: }\end{array}$ & Locomotives & $\begin{array}{c}\text { Railcars I } \\
\text { DMU trainsets }\end{array}$ \\
\hline \multirow[t]{2}{*}{ UIC statistics } & 17640 & 8775 \\
\hline & $67 \%$ & $33 \%$ \\
\hline \multirow[t]{2}{*}{ Jane's World Railways } & 15402 & 7775 \\
\hline & $66 \%$ & $34 \%$ \\
\hline \multirow[t]{2}{*}{ Railfaneurope.net } & $\begin{array}{c}16989 \\
\text { (9773 Mainline, } 7216 \text { Shunting) }\end{array}$ & 7453 \\
\hline & $70 \%$ & $30 \%$ \\
\hline
\end{tabular}

This table identified the EU27 fleet of mainline diesel-electric and dieselhydraulic locomotives as exceeding 11,000 units in 2005. Considerable fleets of modern passenger and freight diesel locomotives exist in France (1500), Germany (1000), the Czech Republic (1200), Poland (1600) and the UK (1000) with recent high levels of investment concentrated on the replacement of the heavy freight type. The flexibility of diesel power to penetrate non-electrified secondary routes and to cheaply achieve interoperability and network acceptance has been recognized by both large and small freight operators who have invested accordingly. Although the number of diesel locomotives dedicated to purely passenger traffic has declined sharply over the past 10 years, on secondary routes their work has been taken over by major investments in new diesel multiple units by French, German, Danish and British regional and local operators. In the same survey, an EU27 fleet of 14,000 diesel multiple unit vehicles was identified of which at least 9000 can be considered to be diesel hydraulic power cars with at least one diesel engine and within the scope of this project. The major national players are the UK with 2400 power cars, Germany with 2300+, the Czech Republic with 1000+ and France with 900 and rising. All these stakeholders are represented in this bid, either as manufacturers and/or operators. The power cars 
are fitted with new or remanufactured engines every $3-5$ years so their ability to accept new technologies will have a marked impact on the speed of take up of the new NRMM Directive [5].

In this scenario, some activities related to conducting a cost-benefit analysis and to developing an LCC model were realized during the FP7 CleanER-D project. They have aimed to quantify the merit of introducing the environmental regulations (Stage IIIB of EU Directive 2004/26/EC) which are proposed for emission control from diesel exhaust gases in railway applications. Also these activities try to create a framework for comparing alternative scenarios for the future of the diesel rail business and its users. It is well known that cost-benefit analysis is expected to provide significant information to policymakers on the impacts of the introduction and implementation of environmental regulations by offering a clear financial assessment based on rigorous economic efficiency. Moreover, it has to be pointed out that the inputs to cost-benefit analysis can be extremely complex and difficult to estimate.

The first sets of standards (Stage IIIA) applied to new engines fitted in rail vehicles were introduced in 2006 and 2009. A more stringent set of standards were about to be introduced in 2012 as Stage IIIB and will apply to new engines fitted to both railcars and locomotives, irrespective of power output.

In a certification test for compliance, engines normally emit less than the standard by a margin to comply the emission limits, also considering the production variability and in-service deterioration. Although a rail vehicle's emission rate can vary throughout its life as the engine ages and as ambient conditions change, the values used in this assessment will be based on fixed emission standards values.

\section{The LCC basic concepts and approach}

Life Cycle Cost is the total cost of ownership of machinery and equipment, including its cost of acquisition, operation, maintenance, conversion, and/or decommission. LCC are summations of cost estimates from inception to disposal for both equipment and projects as determined by an analytical study and estimate of total costs experienced in annual time increments during the project life with consideration for the time value of money. The objective of LCC analysis is to choose the most cost-effective approach from a series of alternatives to achieve the lowest long-term cost of ownership. Procurement costs are widely used as the primary (and sometimes only) criteria for equipment or system selection based on a simple payback period. LCC analysis is required to demonstrate that operational savings are sufficient to justify the investment costs [1].

Generally the topics of a Life Cycle Cost (LCC) analysis involve several stages of the life cycle of the product that is to say the identification of the Customer Requirements (CR) or Engineering Requirements (ER) until its disposal. The model of LCC must be able to manage a deployment of all the major aspects and costs related to each phase of product life. For this purpose, 
different explanatory masks are proposed. In this paragraph some concepts related to requirements that LCC has to respect will be detailed.

Basically the LCC model to be developed must be able to manage a deployment of all the main aspects and costs associated with:

- $\quad$ requirements to satisfy $(\mathrm{CR}, \mathrm{ER})$;

- research and development, design;

- manufacturing, logistics, industrial (industrial logistics);

- $\quad$ operation, maintenance (safety), trade logistics (business logistics) and logistics systems;

- disposal phase.

All these aspects must be treated in accordance with an integrated approach.

The deployment and collection of feedback information of the various aspects related to the life cycle of the product should be conducted in order to ensure the best quality of the results and to reduce the chances of subsequent negative events such costs and/or high maintenance, redesign, rework, damage and more.

The objectives are to have a system that performs all the functions for which it has been made whenever it is required to activate an uninterrupted operation, with the Life Cycle Cost as low as possible. In the event that a fault occurs, it should be easily repaired in a short time. Stakeholders' analysis of Life Cycle Cost are basically the system supplier and customer.

Also in the railway operations, effective lowest life cycle cost is fundamental to the ongoing success of all management issues. Each has a significant impact on cost and performance that could be for example as in the following list:

- maintenance contract framework;

- maintenance strategy: options and selection;

- upgrade: new versus refurbished vehicles.

The use of a life cycle cost (LCC) comparison model as a decision tool for each of the above cases may be considered. The need for the LCC model to be comprehensive and the importance of an effective risk and sensitivity analysis of the outputs is highlighted.

In the specific case of railways, marine or power generation applications, the decision process for the selection of a diesel engine and its integrated system is often based on the "Through Life Cost" (TLC), otherwise known as "Life Cost Cycle" (LCC), since the initial cost is much lower than TLC over the expected life of the investment.

The main parameters that should be considered during the cycle life of the engine are:

- the cost of bought-out consumables required to maintain the engine functions, i.e. fuel and lubricating oil;

- emission-related media required to keep emissions within regulatory limits;

- water treatment.

In addition, the cost of planned maintenance activities to keep the engine in good order has to be considered:

- $\quad$ spare parts such as bearing shells, seals etc.;

- labour costs to carry out the planned maintenance; 
- the cost of operating time lost due to planned maintenance.

These costs can be planned and budgeted but unplanned costs must also be allowed for the cost of unplanned maintenance to keep the engine in good order:

- failed parts such as connecting rod, piston, etc.;

- $\quad$ emergency engineering support for failure analysis etc.;

- labour cost to replace failed parts;

- the cost of operating time lost due to unplanned maintenance.

There are some unique features about the planned maintenance practices for locomotives. As for other mobile power sources, locomotive maintenance activities can be broken down into a number of subcategories such as routine servicing and scheduled maintenance:

- routine service consists of providing the fuel, oil, water, sand (occasionally applied to the rails for added traction), and other expendables necessary for day-to-day operation;

- $\quad$ scheduled maintenance can be classified as light or heavy, with regard to inspection and cleaning of fuel injectors, or to cylinder head and pistons or to cylinder liner replacement.

Moreover, there will be the overhaul, which is a full dismantling of the engine to examine all parts and replace certain parts as per engine manufacturer's instructions and other parts being changed depending on their condition during the inspection. This has been assumed to be required after 10-12 years of service or 35,000 hours, whichever occurs first. The costs of overhaul will typically be a substantial percentage of the first cost, so if overhaul costs are greater than this, engine replacement may prove to be a more economical alternative.

Wherever possible, scheduled maintenance (particularly the lighter maintenance) should be timed to coincide with periodic overall locomotive technical (including safety) inspections, which normally occur at specified intervals and according to the operator's preferred schedule and based on the engine manufacturer's recommendations. Scheduled maintenance is typically at 3 or 6 month intervals.

Unplanned (breakdown) maintenance, which may need to be done in the field, consists of actions necessary to get a locomotive back into service following some form of failure. The new thinking on optimising solutions in the EU and the US has given rise to a tendency among rail operators to diversify maintenance providers.

During the Cleaner-D project, a computer program has been developed, in simple Microsoft Excel spreadsheet format, to work out the life cycle cost for the investment of installing a diesel engine in railway applications [6]. The tool was developed to able to deal with a conventional diesel engine and a modern engine with after-treatment added to the base engine to achieve the emission levels required by IIIB. This LCC model can be applied to both locomotive and DMU engines built to UIC-II, IIIA and IIIB, which cover mainly fuel consumption, oil consumption and maintenance aspects. The addition of after-treatment equipment and the costing of the consumables and maintenance of the added equipment required to achieve Stage EU-IIIB emission control was not 
achievable without these additional pieces of equipment. The model has been developed to consider these additional elements which are needed to enable a Stage IIIB engine to be analysed for its LCC or through-life costs.

The logical approach of this tool gives it a much defined structure. It is structured in sub-models for specific issues dealing with the different cost factors related to changing engine concept to fulfil NRMM Directives requirements. Each sub model addresses a specific aspect; that is research and development's cost, the cost related to changes in railway vehicles design and related issues (e.g. homologation), corrective maintenance costs (costs related to fuel consumption changes, costs related to new maintenance concepts (maintenance plan) and costs related to spare part supply and management, for a new or significantly changed part. Also in [4] a separate evaluation is made to investigate the influence of the different cost elements to gain one single criteria (total costs) and to evaluate the life cycle costs (LCC). From an economic point of view these are the acquisition costs, the costs of maintenance and the cost for the operating fluids, mainly fuel.

\section{LCC tool development and results}

The LCC tool is based on Microsoft Excel $^{\circledR} C$ Macro which allows one to estimate and compare the LCC of different alternative solutions or to perform impact analysis. Such a tool will be used to support the "PESTLE" analysis, to calculate different costs and to produce outputs, to evaluate impact of Phase IIIB compliance and further developments related to innovative solutions.

The decision between the different alternatives of after-treatment to achieve the objectives will be done according to the Life Cycle Cost (LCC). Also a Sensitivity Analysis on a basic cost, i.e. fuel, is implemented.

The tool [8] has been developed to calculate the running costs of current engine builds (with the IIIA or UIC-II stage) and to compare these costs with the new engine builds to Stage IIIB, together with any after-treatment related variable costs.

The tool is based on several steps needed to obtain a detailed summary and comparison of different stages described below.

- Vehicle application selection;

- $\quad$ Engine settings;

- Commercial data;

- $\quad$ Power profile;

- $\quad$ Engine maintenance;

- $\quad$ Proportion of type approval;

- $\quad$ Export PDF summary.

For each engine configuration the user can input different information as shown in Figures 1 and 2. 


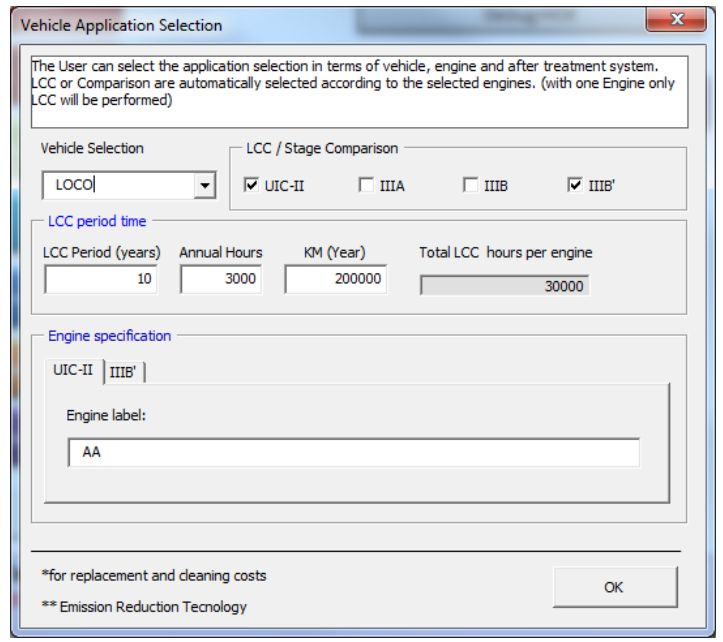

Figure 1: Vehicle application selection.

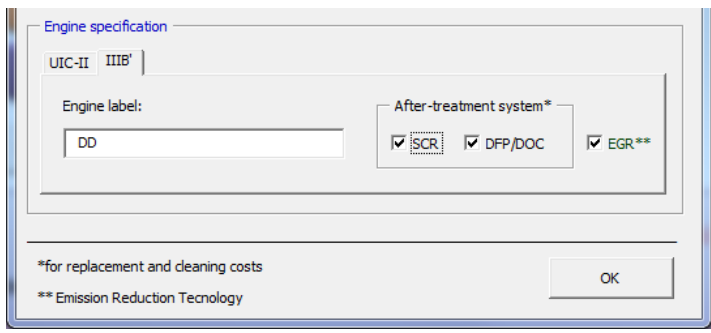

Figure 2: After-treatment system choices.

Then the user can input the fields described in the following table:

Table 2: $\quad$ LCC Engine fields input data.

\begin{tabular}{|l|l|}
\hline Lube oil sump quantity (liter): & sump tank capacity in liters \\
\hline Lube oil change period (hr): & time interval for oil change \\
\hline Engine first cost: & engine initial cost per kw \\
\hline Engine rated brake power kWb: & engine's horsepower before the loss in power \\
\hline Engine rated speed rpm: & $\begin{array}{l}\text { allowable maximum rotative speed of the } \\
\text { engine for continuous reliable performance }\end{array}$ \\
\hline Coolant capacity (liter): & engine cooling capacity in liters \\
\hline Engines per loco & number of each \\
\hline
\end{tabular}

Commercial data are used to calculate annual liquid consumption and to elaborate a sensitivity analysis of fuel price. The user can insert the price and the 
quantity $(\mathrm{kg} / \mathrm{lt})$ of fuel, lube oil and urea. The urea value will be used only for Stage IIIB. Moreover it is possible to insert different fuel prices to elaborate a sensitivity analysis of the price in terms of low price (tax free), retail price and high price.

The user can insert, for each checked engine configuration, the power profile (Figure 3). Different engine consumptions are automatically calculated.

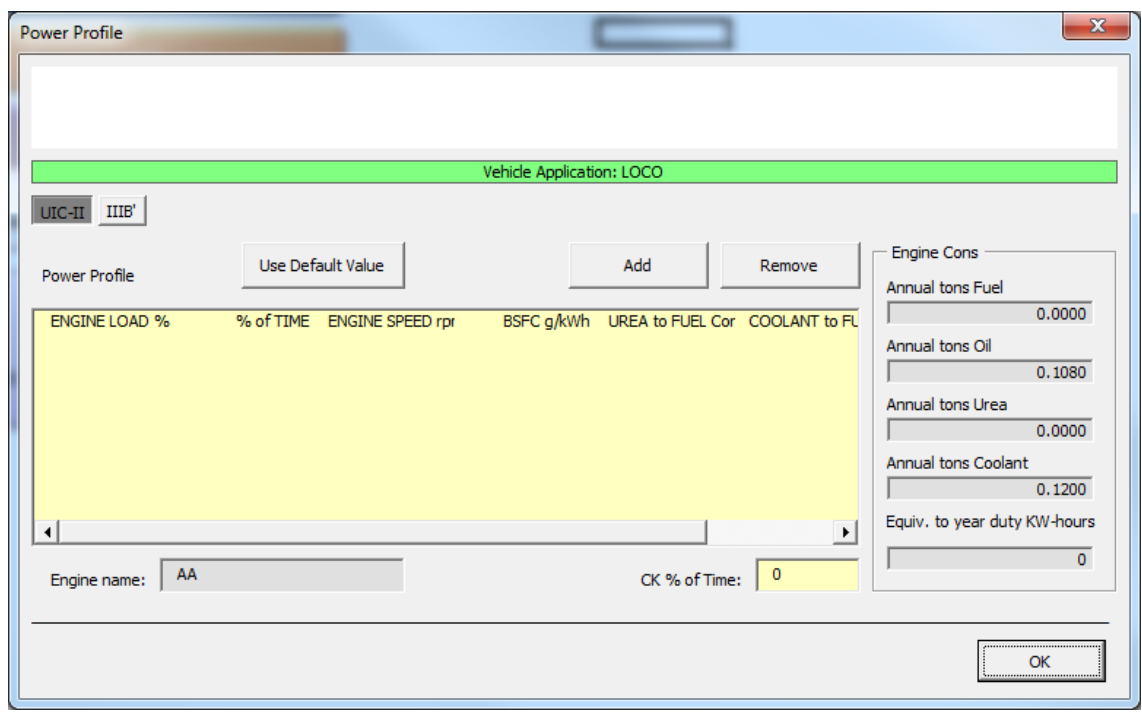

Figure 3: Power profile.

At this stage the user can input the fields described in the following table:

Table 3: $\quad$ LCC User power profile input fields data.

\begin{tabular}{|l|l|}
\hline Engine load \% & $\begin{array}{l}\text { percentage of maximum available torque output } \\
\text { under given conditions }\end{array}$ \\
\hline \% of time & $\begin{array}{l}\text { percentage of time spending at that engine load } \\
\text { speed in revolutions per minute spending at that } \\
\text { engine load; }\end{array}$ \\
\hline Engine speed rpm & $\begin{array}{l}\text { brake specific fuel consumption in } \mathrm{g} / \mathrm{kWh} \text { at that } \\
\text { engine load; }\end{array}$ \\
\hline bSFC g/kWh & $\begin{array}{l}\text { urea consumption as percentage of fuel at that } \\
\text { engine load }\end{array}$ \\
\hline UREA to FUEL cons\% & $\begin{array}{l}\text { coolant consumption as percentage of fuel at that } \\
\text { engine load }\end{array}$ \\
\hline $\begin{array}{l}\text { COOLANT to FUEL } \\
\text { cons\% }\end{array}$ & $\begin{array}{l}\text { oil consumption as percentage of fuel at that } \\
\text { engine load }\end{array}$ \\
\hline OIL to FUEL cons\% \\
\hline
\end{tabular}


In LCC engine maintenance the user can input data related to two child tasks: "corrective maintenance costs" and "maintenance plan costs".

In the "corrective maintenance costs": the user can input all the needed value to perform the corrective maintenance plan (Figure 4). It is possible to input the engine spare costs in terms of MTBF (Mean Time Between Failures), MTTr (Mean Time To repair) and spare costs; in some way it is possible to input the after-treatment system values.

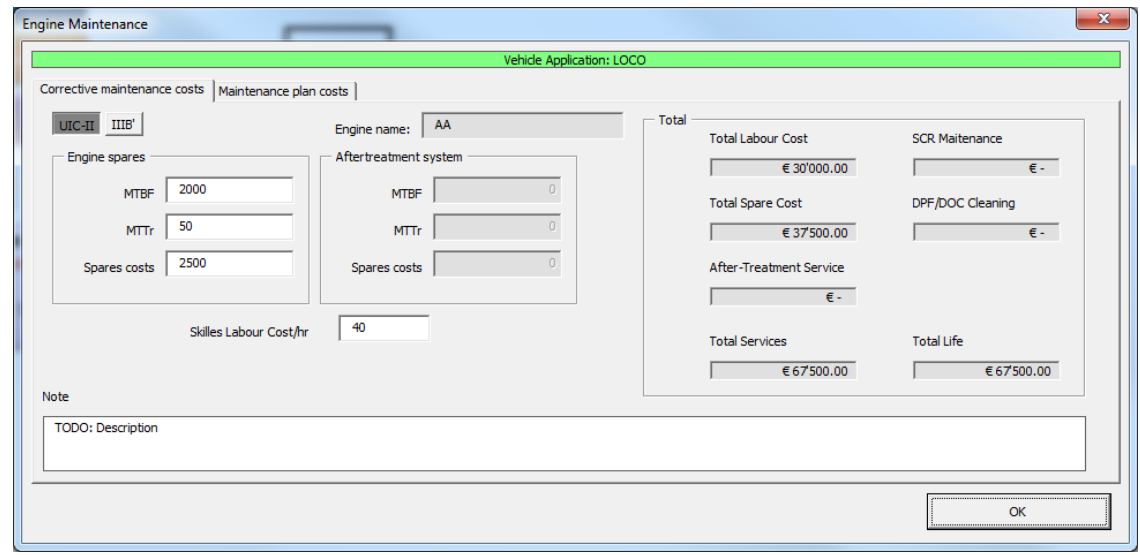

Figure 4: Corrective maintenance cost task.

In the "maintenance plan costs": the user can input all the needed values to perform the preventive maintenance plan. According to the engine and the aftertreatment system chosen the user is guided in the inputted phases, enabling or disabling the after-treatment equipment (as shown in Figure 5).

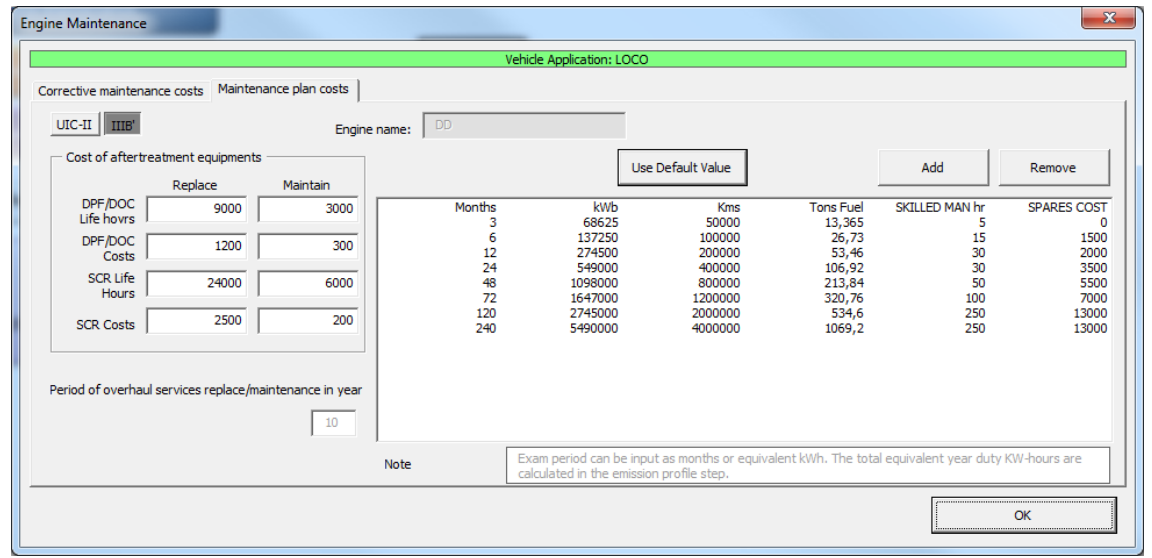

Figure 5: $\quad$ Preventive maintenance plan costs task (IIIB'). 
When all the steps are performed the user can immediately generate and export a complete summary in PDF format (i.e. Figure 6). The tool allows one to create and export in a PDF the report of LCC analysis for a single emissive stage (UIC-II/PREIII A, IIIA, IIIB with or without SCR), or to compare costs for two or more different configurations for after-treatment system, for example UIC-II versus IIIB (with/without SCR system).

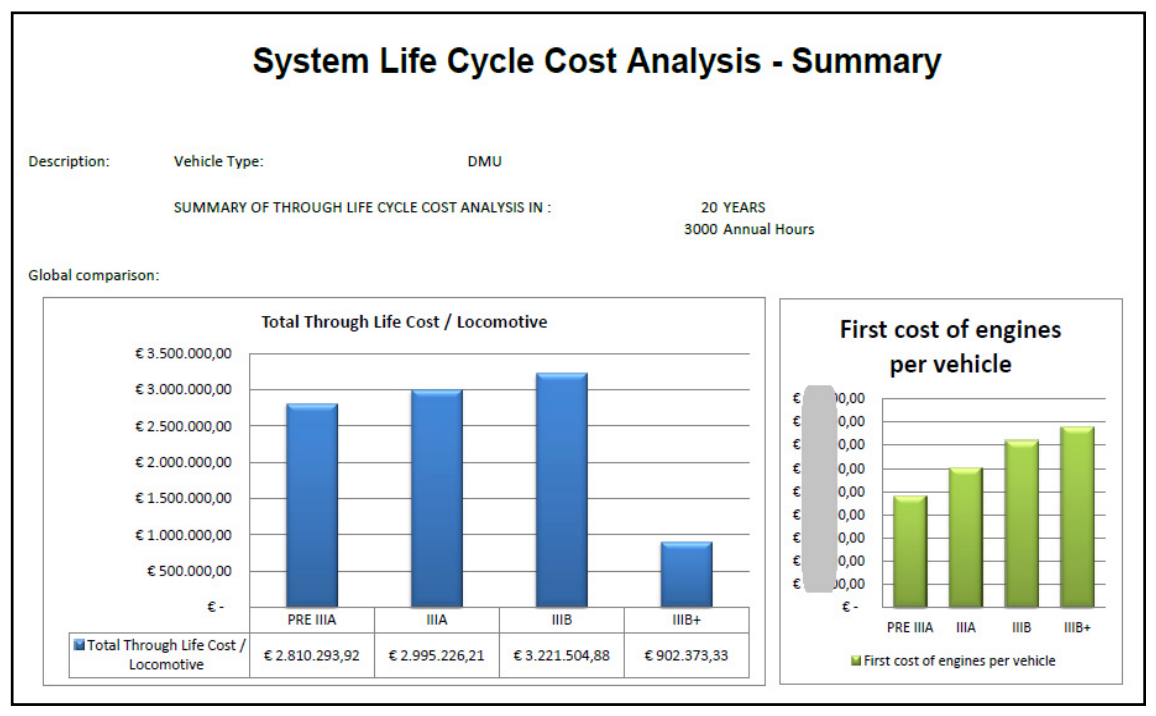

Figure 6: System Life Cycle Cost analysis - summary.

\section{Conclusion}

In the context of FP7 CleanER-D project the characteristics of a LCC model for the new subsystem to fulfil NRMM Directive Stage IIIB Requirements on emission has been investigated taking into account the after treatment device and the emerging technology solutions. As results the Preliminary Cost Factors Characterisation has been developed for the engines compliant with the IIIB Stage in order to allow the evaluation of the Delta-Cost. The model takes in input the maintainability, reliability, and availability of each engine, according to the RAM Model and Analysis. Thus a specific model tool to calculate Delta-Cost Factors has been developed.

The tool allows one to create and export in a PDF report the LCC analysis for a single emissive stage, or to compare costs for two or more different configurations for after-treatment system. The PDF report contains different outputs, tables of summary, graphical charts comparisons, and sensitivity analysis on fuel prices. 


\section{References}

[1] Dhillon B. S., Life Cycle Costing for Engineers, CRC Press Taylor \& Francis Group, ISBN:978-1-4398-1688-2, 2010.

[2] Awalegaonkar K., Britton J., Curtiss C., Dünnwald A., Applying a life-cycle TCO approach to rail assets, edited by Alice Griffiths, McKinsey \& Company, November 2009.

[3] EPA Incremental Cost Estimates for Marine Diesel Engine Technology Improvements, EPA420-R-98-021, 1998.

[4] Schimke, R.; Zimmermann, G.; Beitelschmidt, M.: "Life Cycle Cost Calculations of Diesel-Electric Locomotives with Electrochemical Storage Systems", Energy Efficient Vehicles Technology I, Proceedings to EEVC 2011, Dresden, 30.06.-01.07.2011, S. 57-67.

[5] Halder M., Löchter A., Rail Diesel Study, WP 1 "Status and future development of the diesel fleet" Final Report, July 2005.

[6] Sperandio F., Basso M, "Report on Cost Factor Analysis" Clean European Rail-Diesel (CleanER-D) Project, https://secure.cnc.it/cleaner-d/Docs/CLDD-DAP-055-05.zip.

[7] Al-Sened A., Nolte R., "Cost Benefit Analysis of Technical Options for Emission Reduction", Clean European Rail-Diesel (CleanER-D) Project. https://secure.cnc.it/cleaner-d/Docs/CLD-D-TEC-001-04.pdf.

[8] Della Ragione L., Meccariello G., Sperandio F., Basso M., "User Manual of the LCC Modelling Tool", Clean European Rail-Diesel (CleanER-D) Project, https://secure.cnc.it/cleaner-d/Docs/CLD-D-DAP-174-05.zip. 